\title{
Level of physical activity among teaching and support staff in the education sector in Dohuk, Iraq
}

S.Y. Agha ${ }^{1}$ and S.A. Al-Dabbagh

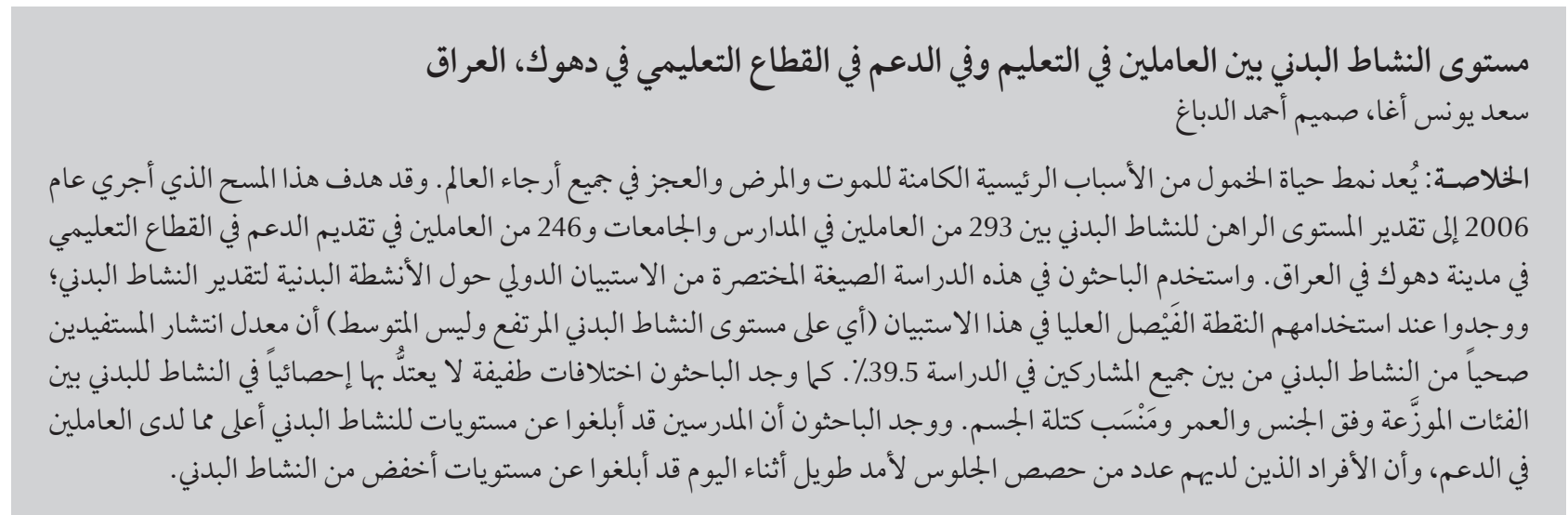

ABSTRACT Sedentary lifestyle is a major underlying cause of death, disease, and disability worldwide. This survey in 2006 aimed to estimate the current level of physical activity among 293 school and university teaching staff and 246 support staff working in the education sector in Dohuk city, Iraq. The short form of the international physical activity questionnaire (IPAQ) was used to estimate physical activity. Using the higher IPAQ cutoff point (i.e. high, not moderate, level of activity) the prevalence of physical activity beneficial to health among all participants was 39.5\%. Small but nonsignificant differences in physical activity were found among sex, age and BMI categories. Teachers reported significantly higher physical activity levels than support staff, and individuals with longer average sitting times per day reported significantly lower levels of physical activity.

Niveau d'activité physique du personnel enseignant et administratif dans le secteur de l'éducation à Dohuk (Iraq)

RÉSUMÉ Le mode de vie sédentaire est l'une des principales causes sous-jacentes de mortalité, de morbidité et d'incapacité dans le monde. La présente enquête, réalisée en 2006, avait pour objectif d'estimer le niveau d'activité physique d'alors de 293 enseignants en écoles secondaires et en universités et de 246 membres du personnel administratif dans le secteur de l'éducation à Dohuk (Iraq). La version courte du questionnaire international sur l'activité physique a été utilisée pour mesurer cet élément. En utilisant la valeur seuil la plus élevée du questionnaire, (c'est-à-dire une activité physique intense et non modérée), la prévalence d'une activité physique bénéfique pour la santé a été estimée à 39,5\% pour tous les participants. Des différences minimes non significatives ont été retrouvées en fonction du sexe, de l'âge et de l'indice de masse corporelle. Les enseignants ont déclaré des niveaux d'activité physiques supérieurs à ceux du personnel administratif et les individus passant en moyenne le plus de temps en position assise par jour ont déclaré avoir des niveaux d'activité physique nettement plus faibles. 


\section{Introduction}

Regular participation in physical activity is associated with a reduced risk of premature mortality, coronary heart disease, hypertension, cancer, diabetes mellitus, obesity, emotional stress and musculoskeletal disorders. Sedentary lifestyles or physical inactivity, on the other hand, are a major underlying cause of death, disease and disability $[1,2]$. Approximately 2 million deaths every year are attributable to physical inactivity. The world is witnessing a significant increase in the burden of noncommunicable diseases such as cardiovascular diseases, cancer, diabetes and chronic respiratory diseases. These relate closely to changes in lifestyle, mainly in tobacco use, physical inactivity and unhealthy diets. Meanwhile, the burden of noncommunicable diseases is shifting to poorer countries. [3].

Obesity/overweight rates are increasing among young people and middle-aged adults [2-4]. This is related in part to lack of leisure time physical activity, but is more likely the result of increasing hours spent in sedentary behaviours, e.g. watching television, using computers and passive modes of transport such as cars and buses. Decreasing physical activity and reductions in physical education programmes in schools is an alarming trend worldwide.

An assessment of current levels of physical activity and inactivity is critical for defining the extent of the problem, guiding public health efforts and evaluating progress toward national health objectives [5]. This survey in Dohuk city, Iraq aimed to estimate the current level of physical activity among the teaching and nonteaching staff of the primary, secondary and higher education institutions.

The study will provide background data for improving the level of physical activity among the studied population.

\section{Methods}

The survey was conducted in Dohuk city, the centre of Dohuk governorate. The city is in a semi-mountainous area in northern Iraq and has a population of around 400 000. Data were collected over 3 months from 15 February to 30 April 2006 during moderate weather conditions and from 15 June to 30 June 2006 during hot weather.

\section{Sample}

At the time of the survey, the city had 114 primary and secondary schools and a university with 10 colleges. Multistage quota sampling was used to obtain balanced subsamples from the various education offices. In the first stage, the directorate of education and the university presidency offices (each around 150 staff) were surveyed to represent nonteaching staff, e.g. supervisors, administrators, engineers and others. To represent the teaching staff, the second stage included 2 randomly selected subsamples each with around 150 staff from 8 primary and secondary schools and 3 university colleges. Two colleges were surveyed during the hot season in June, because university holidays do not start until July, while school holidays start in June. Thus, the total sample planned to be surveyed was 600 .

\section{Data collection}

- The international physical activity questionnaire (IPAQ) short form was used in the current survey for estimation of physical activity level. This is an instrument designed primarily for population surveillance of physical activity among adults aged 15-69 years [6]. An Arabic version of IPAQ was taken from the IPAQwebsite [6] and translated into the local Kurdish language. To ensure similarity to the original English version, both versions were back-translated, and then used to train the one physician who conducted the survey. During the survey, the physician briefly explained the purpose of the survey, obtained verbal consent for participation and completed the questionnaire by direct interview.

The IPAQ short form asks about specific types of physical activity during the 7 days preceding the interview, under the following 4 domains: leisure time; domestic and gardening; workrelated; and transport-related physical activities. The 3 types of activity assessed are: walking; moderate-intensity activities (e.g., gardening, washing the car or clothes by hand, or bicycling at normal speed); and vigorous-intensity activities (e.g. heavy weightlifting, running or swimming). The items in the short IPAQ form are structured to provide separate scores on these activities. Computation of the total score requires summation of the duration (in minutes) and frequency (days) of these activities. The volume of activity can then be computed by weighting each type of activity by its energy requirements defined in metabolic equivalents (METs) to yield a score in MET-minutes. METs are multiples of the resting metabolic rate. Physical activity can then be reported as a categorical variable and 3 levels have been proposed [6].

- Low: No activity reported or some activity reported but not enough to meet categories 2 or 3 .

- Moderate: Any of the following 3 criteria: $\geq 3$ days of vigorous activity of at least 20 minutes/day or $\geq 5$ days of moderate-intensity activity and/or walking of at least 30 minutes/day or $\geq 5$ days of any combination of walking, moderate-intensity or vigorousintensity activities achieving at least 600 MET minutes/week.

- High: Any of the following 2 criteria: vigorous-intensity activity on at least 3 days and accumulating at least 1500 MET-minutes/week or $\geq 7$ days of any combination of walking, moderate- or vigorous-intensity activities accumulating at least 3000 METminutes/week. 
Weight was measured using an electronic scale to the nearest $0.5 \mathrm{~kg}$. Height was measured with a stadiometer to the nearest $1.0 \mathrm{~cm}$. Body mass index (BMI) was categorized as: below normal weight $\left(<18.5 \mathrm{~kg} / \mathrm{m}^{2}\right)$; normal weight $\left(18.5-24.9 \mathrm{~kg} / \mathrm{m}^{2}\right)$; overweight $\left(25.0-29.9 \mathrm{~kg} / \mathrm{m}^{2}\right)$; and obese $(\geq 30.0$ $\left.\mathrm{kg} / \mathrm{m}^{2}\right)[7]$.

Age was grouped into 3 categories: $15-29$ years (youth); 30-44 years; and 45-64 years [8].

\section{Data analysis}

Continuous variables were categorized and frequency distribution tables organized to describe them. Because the physical activity score in MET-minutes was found largely positively skewed, physical activity was displayed as a categorical variable and then cross-tabulated with demographic and physical factors; the chi-squared test was used to test the association between physical activity level and those factors. The significance level was set at $P<0.05$. Analysis of data was performed using SPSS, version 15.

\section{Results}

Of the 600 staff members planned to be surveyed, 543 were available on survey days and 539 agreed to participate in the study, 269 males and 270 females.

As Table 1 shows, teaching staff comprised $54.4 \%$ of the study population. All respondents were surveyed during February, March and April, except for $67(12.4 \%)$ university teachers who were surveyed in June.

The age of respondents ranged from 18-64 years (Table 2). Over $80 \%$ of the respondents were below age 45 years; more males than females were aged 45-64 years. Two-thirds of the study population were sedentary for 5 hours or more. The prevalence of overweight was $36.2 \%$ and of obesity was $14.8 \%$; men tended to be more overweight than obese compared with women.

\begin{tabular}{|c|c|c|c|c|}
\hline \multicolumn{5}{|c|}{$\begin{array}{l}\text { Table } 1 \text { Distribution of the study population according to type and place of work, } \\
\text { by sex }\end{array}$} \\
\hline \multirow[t]{2}{*}{ Type and place of work } & \multicolumn{2}{|c|}{$\begin{array}{c}\text { Total } \\
(n=539)\end{array}$} & \multirow{2}{*}{$\begin{array}{c}\text { Males } \\
(n=269) \\
\%\end{array}$} & \multirow{2}{*}{$\begin{array}{c}\begin{array}{c}\text { Females } \\
(n=270)\end{array} \\
\%\end{array}$} \\
\hline & No. & $\%$ & & \\
\hline \multicolumn{5}{|l|}{ Nonteaching (support) staff } \\
\hline Office of directorate of education & 128 & 23.7 & 24.8 & 22.6 \\
\hline Office of university president & 118 & 21.9 & 16.4 & 27.3 \\
\hline Subtotal & 246 & 45.6 & 41.3 & 49.9 \\
\hline \multicolumn{5}{|l|}{ Teaching staff } \\
\hline School & 155 & 28.8 & 20.8 & 36.7 \\
\hline University & 138 & 25.6 & 37.9 & 13.4 \\
\hline Subtotal & 293 & 54.4 & 58.7 & 50.1 \\
\hline
\end{tabular}

Three-quarters of all staff (74.0\%) were classified as highly or moderately active using the IPAQ cutoffs, while $39.5 \%$ of staff were highly active.

Table 3 shows more than half of schoolteachers (56.8\%) reported high physical activity compared with around one-third of other staff $(P<0.001)$. When the teaching staff were compared with the support staff, again the former were significantly more active than the latter $(P<0.001)$. Women seemed to be more active than men, with $41.5 \%$ of women reporting high physical activity compared with $37.5 \%$ of men, although the difference did not reach statistical significance. Those aged 15-29 years were more active ( $42.3 \%$ in the high physical activity category) than those aged 30-44 and 45-64 years (37.0\% and $37.8 \%$ in the high physical activity category, respectively), but again the differences did not reach statistical significance.

Table 3 confirms that highly active persons had significantly fewer sitting hours than less active ones; half of the highly active individuals reported $<5$ sitting hours per day compared with about one-quarter of the less active. Among the various BMI categories, small nonsignificant differences existed, but, interestingly, a high proportion of obese people reported high physical activity (42.5\%). High physical activity was significantly more often reported by the staff surveyed during the moderate weather season than by those surveyed in hot summer (40.9\% versus $29.9 \%$ ).

\section{Discussion}

Although physical inactivity is a global concern, the diversity of physical activnational and international comparisons. Most studies have focused on leisure time physical activity, while physical activity at work, home and during transport has not been assessed $[9,10]$. Progress has been made recently in developing an international measure of physical activity - the IPAQ - as a simple instrument to assess overall physical activity and to provide information for use in population health surveillance systems. This was followed by extensive reliability and validity testing worldwide [11-15]. The use of a standard measure allows comparisons within a country, between neighbouring countries and at a regional and global level. The final results of those studies recommended the use of the IPAQ short "last 7 days" form, as used in our study, in national and regional prevalence studies [11].

Recognizing that virtually no data are available on the prevalence of physical activity in Iraq [16], we attempted to estimate the current level of physical activity among the teaching ity measures currently in use prevent 


\begin{tabular}{|c|c|c|c|c|}
\hline \multirow[t]{2}{*}{ Variable } & \multicolumn{2}{|c|}{$\begin{array}{c}\text { Total } \\
(n=539)\end{array}$} & \multirow{2}{*}{$\begin{array}{c}\begin{array}{c}\text { Male } \\
(n=269) \\
\%\end{array} \\
\end{array}$} & \multirow{2}{*}{$\begin{array}{c}\text { Female } \\
(n=270) \\
\%\end{array}$} \\
\hline & No. & $\%$ & & \\
\hline \multicolumn{5}{|l|}{ Age (years) } \\
\hline $15-29$ & 241 & 44.7 & 31.7 & 57.7 \\
\hline $30-44$ & 208 & 38.6 & 43.5 & 33.7 \\
\hline $45-64$ & 90 & 16.7 & 24.8 & 8.6 \\
\hline \multicolumn{5}{|c|}{ Level of physical activity ${ }^{a}$} \\
\hline High & 213 & 39.5 & 37.5 & 41.5 \\
\hline Moderate & 186 & 34.5 & 35.3 & 33.7 \\
\hline Low & 140 & 26.0 & 27.3 & 24.8 \\
\hline \multicolumn{5}{|c|}{ Sitting time (hours per day) } \\
\hline $0.5-4.5$ & 178 & 33.0 & 29.7 & 36.3 \\
\hline $5.0-9.5$ & 289 & 53.6 & 58.3 & 48.9 \\
\hline$\geq 10.0$ & 72 & 13.4 & 12.0 & 14.8 \\
\hline \multicolumn{5}{|l|}{$B M I\left(k g / m^{2}\right)$} \\
\hline$<18.5$ & 16 & 3.0 & 2.6 & 3.4 \\
\hline 18.5-24.9 & 248 & 46.0 & 44.9 & 47.1 \\
\hline $25.0-29.9$ & 195 & 36.2 & 38.7 & 33.7 \\
\hline$\geq 30.0$ & 80 & 14.8 & 13.6 & 16.0 \\
\hline
\end{tabular}

aInternational physical activity questionnaire short form cutoffs [6].

and nonteaching staff of the primary, secondary and higher education institutions in Dohuk city. Using the conventional classification of moderate or high physical activity-i.e. the cutoff point at moderate physical activity - threequarters of our respondents (74.0\%) would be classified as physically active. This is a higher than levels reported for the USA (45.9\%) [17], Australia (57\%) [18] or the world (15\%-40\%) [4]. This may be explained as follows. The criteria for physical activity levels mentioned in the methods section of this study were set taking into account that IPAQ asks questions in all domains of daily life, resulting in higher median MET-minutes estimates than would have been estimated from leisure time participation alone. Given that measures such as IPAQ assess total physical activity in all domains, the public health recommendation for "leisure time physical activity" based on 30 minutes on most days will be achieved by most adults in a population.
Although widely accepted as a goal, in absolute terms, 30 minutes of moderate intensity activity is low and broadly equivalent to the background or basal levels of activity adult individuals would accumulate in a day. Therefore, a higher cutoff point-i.e. high rather than moderate orhigh physical activity levelasclassified by the IPAQ scoring system - has been proposed to describe the levels of physical activity associated with health benefits [6]. According to this new cutoff point, only $39.5 \%$ of the study population would be considered physically active and meeting health requirements. This level is similar to developed countries such as Switzerland (37\%) [19], but is still high compared with Saudi Arabia (23.5\%, 19.1\%) [20,21], South Korea (16.6\%) [22], Taiwan (14\%) [23] and Brazil (3.3\%) [24]; the latter 4 surveys are similar to the current study in using self-reports of physical activity, but they only measured leisure time or recreational physical activity. We need to wait for local or regional surveys that use this stricter IPAQ cutoff to make better comparisons. It is also possible that respondents in the current survey overestimated their physical activity, an observation that was made in IPAQ's 12 countries study [11]. Overreporting of physical activity in population samples has been found to be a serious problem, and a need exists to develop the IPAQ further to solve the apparent overreporting by sedentary individuals $[25,26]$.

Apart from methodology issues, other possible explanations for the high physical activity level reported in this survey include the favourable season during which most of participants were surveyed. The tradition of families in Dohuk is to spend spring in picnics where opportunities for physical activity and sports are high. Another explanation could have been the high price of fuel at the time of the survey, which might have reduced the use of private cars, replacing it by walking. It should be emphasized that high levels of physical activity are not necessarily achieved by being vigorously active; in fact most people in the high physical activity category in the current study achieved this by walking and/or doing moderate activities of sufficient duration to classify them as such. Physical activity does not need to be vigorous to provide health benefits; moderate intensity physical activity is considered a vital component of a healthy lifestyle for people of all ages and abilities, being more readily adopted and maintained than vigorous physical activity [2].

Teachers, in particular schoolteachers,reported significantlyhigherphysical activity in the current survey compared with the support staff. This could be due to the clerical desk-bound nature of work for many support staff. Many teachers mentioned that they walked several hours while teaching. This agrees with the finding that individuals with longer average sitting times per day reported significantly less physical activity than those with shorter sitting times. 


\begin{tabular}{|c|c|c|c|c|c|}
\hline \multirow[t]{2}{*}{ Variable } & \multirow{2}{*}{$\begin{array}{l}\text { Total } \\
\text { No. }\end{array}$} & \multicolumn{3}{|c|}{ Physical activity levela } & \multirow[t]{2}{*}{$P$-value } \\
\hline & & $\begin{array}{c}\text { Low } \\
\%\end{array}$ & $\begin{array}{c}\text { Moderate } \\
\%\end{array}$ & $\begin{array}{c}\text { High } \\
\%\end{array}$ & \\
\hline \multicolumn{6}{|l|}{ Place of work } \\
\hline Office of directorate of education & 128 & 28.1 & 39.8 & 32.0 & \multirow[t]{4}{*}{$<0.001$} \\
\hline Office of university president & 118 & 32.2 & 39.0 & 28.8 & \\
\hline School & 155 & 11.6 & 31.6 & 56.8 & \\
\hline University & 138 & 34.8 & 29.0 & 36.2 & \\
\hline \multicolumn{6}{|l|}{ Type of work } \\
\hline Nonteaching & 256 & 30.1 & 39.4 & 30.5 & \multirow[t]{2}{*}{$<0.001$} \\
\hline Teaching & 293 & 22.5 & 30.4 & 47.1 & \\
\hline \multicolumn{6}{|l|}{$\operatorname{Sex}$} \\
\hline Male & 269 & 27.1 & 35.3 & 37.5 & \multirow[t]{2}{*}{0.634} \\
\hline Female & 270 & 24.8 & 33.7 & 41.5 & \\
\hline \multicolumn{6}{|l|}{ Age (years) } \\
\hline $15-29$ & 241 & 23.7 & 34.0 & 42.3 & \multirow{3}{*}{0.578} \\
\hline $30-44$ & 208 & 26.4 & 36.5 & 37.0 & \\
\hline $45-64$ & 90 & 31.1 & 31.1 & 37.8 & \\
\hline \multicolumn{6}{|l|}{ Sitting time (hours per day) } \\
\hline $0.5-4.5$ & 178 & 16.3 & 34.3 & 49.4 & \multirow{3}{*}{$<0.001$} \\
\hline $5.0-9.5$ & 289 & 26.6 & 34.3 & 39.1 & \\
\hline$\geq 10.0$ & 72 & 47.2 & 36.1 & 16.7 & \\
\hline \multicolumn{6}{|l|}{$B M I\left(\mathrm{~kg} / \mathrm{m}^{2}\right)$} \\
\hline$<18.0$ & 16 & 31.3 & 31.3 & 37.5 & \multirow{4}{*}{0.750} \\
\hline $18.0-24.9$ & 248 & 25.0 & 35.9 & 39.1 & \\
\hline $25.0-29.9$ & 195 & 24.6 & 36.4 & 39.0 & \\
\hline$\geq 30.0$ & 80 & 31.3 & 26.2 & 42.5 & \\
\hline \multicolumn{6}{|l|}{ Season of survey } \\
\hline Spring & 472 & 23.3 & 35.8 & 40.9 & \multirow{2}{*}{$<0.001$} \\
\hline Summer & 67 & 44.8 & 25.3 & 29.9 & \\
\hline
\end{tabular}

a International physical activity questionnaire short form cutoffs [6].

The desk-bound nature of support staff work could have contributed to this inverse relation. The problem of sedentary working populations has been well recognized and desk-based exercises and on-site physical activities have been recommended as useful solutions [27]. Support staff, including administrators and engineers, need to be involved in physical activity programmes for the sake of their own health, and in order to be convinced of the importance of promoting and sustaining a safe environment for physical activity for children and adolescents. With increased opportunities for physical activity, e.g. playgrounds and playtime, students may opt to selectively engage in these activities instead of more inactive behaviours [28].

Weather or the time of year apparently impacts all socioeconomic groups as a barrier to physical activity [29]. Cold weather has been found to have modest impeding effects on physical activity [30]. Another study which used selfreports ofphysicalactivity found noassociations with weather [31]. While these studies done in industrialized countries have taken into account the effect of low temperature, rain, snow or wind, the current study found significantly fewer people were physically active during hot weather. Environmental temperatures up to $45^{\circ} \mathrm{C}$ during summer in Dohuk usually prompt an increase in the use of private cars and a decrease in physical activity. This is especially the case when fuel becomes available and cheap, as occurred in June 2006 when a subsample of the study population was being surveyed. Environmentally conditioned playgrounds and sport facilities should be made available in schools and universities in our country.

Contrary to several reports of less physical activity among women $[17,32-34]$, our study found women to be more active than men, though this 
was not statistically significant. Working women also appeared to have fewer sitting hours than men. This may be explained by the younger age of women in the current study, and the customs of the local society, where women carry out most of the household requirements of the family. A major improvement in questionnaire assessment of physical activity in IPAQ was the inclusion of household sources of activity, which may be the primary context for physical activity among women in our culture. A study in a rural county in the United States also found women to be more active than men [35].
We found young people to be more active than the older age groups. The difference was statistically not significant, but it does follow the worldwide pattern [2]. Irwin et al. found that the trend for overestimating energy expenditure increases with ageing and obesity and that the trend for underestimating energy expenditure increases as physical activity level increases [36]. This might have obscured a significant association in the current study between physical activity on the one hand, and age and low BMI on the other.

Half of our respondents were either overweight or obese. Overweight and obesity levels were similar to those of developed countries $[17,18,37]$, supporting the idea that Dohuk city is advanced in the spectrum of epidemiological transition [38]. Differences among various BMI categories were not statistically significant in the current study; it is possible that obese individuals who reported high activity had overestimated their activity, which agrees with Irwin et al.'s findings [36]. Maintaining ideal body weight is important in preventing a decline in overall health and physical functioning. Regular exercise can reduce the risk of health decline even among individuals who cannot achieve ideal weight [39].

\section{References}

1. Health and development through physical activity and sport. Geneva, World Health Organization, 2003:1-3 (WHO/NMH/ $\mathrm{NPH} / \mathrm{PAH} / 03.2$ ).

2. Physical activity and health: a report of the Surgeon General. Atlanta, Georgia, US Department of Health and Human Services, Centers for Disease Control, 1996:4-8.

3. World health day 2002. Move for health. Report. Geneva, World Health Organization, 2002:8 (WHO/NMH/NPH/ WHD/02.13).

4. World health report 2002: reducing risks, promoting healthy life. Geneva, World Health Organization, 2002:8-10.

5. Physical activity resources for health professionals: data and surveillance. Atlanta, Georgia, US Department of Health and Human Services, Centers for Disease Control, 2006.

6. Guidelines for data processing and analysis of the International Physical Activity Questionnaire (IPAQ) - short and long forms. IPAQ Research Committee (http://www.ipaq.ki.se/scoring. pdf, accessed 12 October 2010).

7. Obesity: preventing and managing the global epidemic. Report of a WHO consultation. Geneva, World Health Organization, 2000:8-9 (WHO Technical Report Series No. 894).

8. US Census Bureau. Global population profile: 2002. Washington DC, US Government Printing Office, 2004:A20 (International Population Reports WP/02).

9. Committee on Physical Activity. Health, Transportation, and Land Use of the Transportation Research Board and the Institute of Medicine of the National Academies. Does the built environment influence physical activity? Examining the evidence. Washington DC, National Academy of Sciences, 2005:59 (Transportation Research Board Special Report No. 282).

10. Khaw KT et al. Work and leisure time physical activity assessed using a simple, pragmatic, validated questionnaire and incident cardiovascular disease and all-cause mortality in men and women: The European Prospective Investigation into Cancer in Norfolk prospective population study. International Journal of Epidemiology, 2006, 35:1034-1043.

11. Craig $\mathrm{CL}$ et al. International physical activity questionnaire: 12country reliability and validity. Medicine and Science in Sports and Exercise, 2003, 35:1381-1395.

12. Qu NN, Li KJ. [Study on the reliability and validity of international physical activity questionnaire (Chinese vision, IPAQ)].
Zhonghua Liu Xing Bing Xue Za Zhi, 2004, 25:265-268 [in Chinese].

13. Ekelund $U$ et al. Criterion-related validity of the last 7-day, short form of the International Physical Activity Questionnaire in Swedish adults. Public Health Nutrition, 2006, 9:258-265.

14. Speck BJ, Looney SW. Self-reported physical activity validated by pedometer: a pilot study. Public Health Nursing (Boston, Mass), 2006, 23:88-94.

15. Booth ML. Assessment of physical activity: an international perspective. Research Quarterly for Exercise and Sport, 2000, 71(Suppl):S114-S120.

16. Al-Hazzaa HM. Prevalence of physical inactivity in Saudi Arabia: a brief review. Eastern Mediterranean Health Journal, 2004, 10:663-670.

17. Centers for Disease Control and Prevention (CDC). Adult participation in recommended levels of physical activity-United States, 2001 and 2003. Morbidity and Mortality Weekly Report, 2005, 54:1208-1212.

18. Armstrong T, Bauman A, Davies J. Physical activity patterns of Australian adults: results of the 1999 national physical activity survey. Canberra, Australian Institute of Health and Welfare, 2000:22-31.

19. Martin B et al. Physical activity in the Swiss population: prevalence data and associations with health. Sportmedizin und Sporttraumatologie, 2000, 48(2):87-88.

20. Al-Shahri M, Al-Almaei S. Promotion of physical exercise by primary health care physicians in Riyadh city. Saudi Medical Journal, 1998, 19:67-69.

21. Al-Refaee S, Al-Hazzaa HM. Physical activity profile of adult males in Riyadh City. Saudi Medical Journal, 2001, 22:784-789.

22. Cho MH. The strength of motivation and physical activity level during leisure time among youth in South Korea. Youth and Society, 2004, 35:480-494.

23. Ku PW et al. Prevalence of leisure-time physical activity in Taiwanese adults: results of four national surveys, 2000-2004. Preventive Medicine, 2006, 43:454-457.

24. Monteiro CA et al. A descriptive epidemiology of leisure-time physical activity in Brazil, 1996-1997. Revista Panamericana de Salud Pública, 2003, 14:246-254.

25. Rzewnicki R, Auweele YV, De Bourdeaudhuij I. Addressing overreporting on the International Physical Activity Question- 
naire (IPAQ) telephone survey with a population sample. Public Health Nutrition, 2003, 6:299-305.

26. Fogelholm M et al. International Physical Activity Questionnaire: validity against fitness. Medicine and Science in Sports and Exercise, 2006, 38:753-760.

27. Schneider S, Becker S. Prevalence of physical activity among the working population and correlation with work-related factors: results from the first German National Health Survey. Journal of Occupational Health, 2005, 47:414-423.

28. Gordon-Larsen P, McMurray RG, Popkin BM. Determinants of adolescent physical activity and inactivity patterns. Pediatrics, 2000, 105:e83.

29. Burton NW, Turrell G, Oldenburg B. Participation in recreational physical activity: why do socioeconomic groups differ? Health Education and Behavior, 2003, 30:225-244.

30. Chan CB, Ryan DAJ, Tudor-Locke C. Relationship between objective measures of physical activity and weather: a longitudinal study. International Journal of Behavioral Nutrition and Physical Activity, 2006, 3:21.

31. King AC et al. Personal and environmental factors associated with physical inactivity among different racial-ethnic groups of U.S. middle-aged and older-aged women. Health Psychology, 2000, 19:354-364

32. Gomes VB, Siqueira KS, Sichieri R. Atividade fisica em uma amostra probabilística da população do Municipio do Rio de Janeiro [Physical activity in a probabilistic sample in the city of Rio de Janeiro]. Cadernos de Saude Pública, 2001, 17:969-976.
33. Muntner P et al. Prevalence of physical activity among Chinese adults: results from the International Collaborative Study of Cardiovascular Disease in Asia. American Journal of Public Health, 2005, 95:1631-1636.

34. Belander O, Torstveit MK, Sundgot-Borgen J. Er unge norske kvinner aktive nok? [Are young Norwegian women sufficiently physically active?]. Tidsskrift for Den Norske Laegeforening, 2004, 124:2488-2489.

35. Eaton $\mathrm{CB}$ et al. Self-reported physical activity in a rural county: a New York county health census. American Journal of Public Health, 1994, 84:29-32.

36. Irwin ML, Ainsworth BE, Conway JM. Estimation of energy expenditure from physical activity measures: determinants of accuracy. Obesity Research, 2001, 9:517-525.

37. Colucciello $\mathrm{M}$ et al. Prevalenza dei fattori di rischio per le malattie ischemiche del cuore in una popolazione adulta del Nord Italia [Prevalence of risk factors for ischemic heart disease in a northern Italian adult population]. Annali d'Igiene, 2006, 18:23-30.

38. Agha SYA, Mohamad JB, Abdullah QH. Registered mortality and cardiovascular mortality in Dohuk province. Zanco Journal for Medical Sciences, 2001, 5:1-13.

39. He XZ, Baker DW. Body mass index, physical activity, and the risk of decline in overall health and physical functioning in late middle age. American Journal of Public Health, 2004, 94:1567-1573.

\section{Physical inactivity is the fourth leading risk factor for global mortality}

Globally, $6 \%$ of deaths are attributed to physical inactivity. This follows high blood pressure (13\%), tobacco use (9\%) and is equal to high blood glucose (6\%). Moreover, physical inactivity is the main cause for approximately $21-25 \%$ of breast and colon cancers, $27 \%$ of diabetes and $30 \%$ of ischaemic heart disease burden.

WHO developed the Global Recommendations on Physical Activity for Health with the overall aim of providing national and regional level policy makers with guidance on the dose-response relationship between the frequency, duration, intensity, type and total amount of physical activity needed for the prevention of noncommunicable diseases.

The recommendations address 3 age groups: 5-17 years old; $18-64$ years old; and 65 years old and above. The recommendations for each age group can be downloaded at: http://www.who.int/dietphysicalactivity/factsheet recommendations/en/index.html 